\title{
Copper deficit as a potential pathogenic factor of reduced bone mineral density and severe tooth wear
}

\author{
T. Sierpinska $\cdot$ J. Konstantynowicz $\cdot$ K. Orywal $•$ \\ M. Golebiewska • M. Szmitkowski
}

Received: 10 February 2013 / Accepted: 30 May 2013 /Published online: 25 June 2013

(C) The Author(s) 2013. This article is published with open access at Springerlink.com

\begin{abstract}
Summary The study evaluated if men and women with severe tooth wear were at increased risk of general bone loss. Enamel biopsies obtained from 50 subjects aged $47.5 \pm 5$ years showed decreased copper content, which was associated with reduced spine bone mineral density, suggesting deficits of this trace element contributing to bone demineralization, enamel attrition, and deteriorated quality of mineralized tissues.

Introduction The objective of this cross-sectional study was to assess associations between enamel trace minerals and bone mineral density (BMD) in severe tooth wear. We hypothesized that similar factors contributed to both the excessive abrasion of dental enamel and reduced BMD in subjects with tooth wear.

Methods Fifty patients aged $47.5 \pm 5$ years with severe tooth wear and 20 age-, sex-, and body mass index (BMI)-matched healthy volunteers with normal dental status were studied regarding dietary intakes of trace elements, serum and salivary copper $(\mathrm{Cu})$, zinc $(\mathrm{Zn})$, and calcium $(\mathrm{Ca})$ concentrations, and serum PTH, osteocalcin, and hydroxyvitamin D levels. Tooth
\end{abstract}

Dr. Teresa Sierpinska and Dr. Jerzy Konstantynowicz contributed equally to this paper.

T. Sierpinska $\cdot$ M. Golebiewska

Department of Prosthetic Dentistry,

Medical University of Bialystok, Bialystok, Poland

J. Konstantynowicz

Department of Pediatrics and Developmental Disorders,

Medical University of Bialystok, Bialystok, Poland

K. Orywal $\cdot$ M. Szmitkowski

Department of Biochemical Diagnostics,

Medical University of Bialystok, Bialystok, Poland

J. Konstantynowicz ( $\square)$

Department of Pediatrics and Developmental Disorders,

Medical University of Bialystok Children's Teaching Hospital,

Waszyngtona Street 17, 15-274 Bialystok, Poland

e-mail: jurekonstant@o2.pl wear was determined using clinical examination based on standard protocol according to Smith and Knight. In all subjects, acid biopsies of the maxillary central incisors were carried out to assess mineral composition of the enamel. Atomic absorption spectroscopy with an air/acetylene flame was used to measure $\mathrm{Ca}$ and $\mathrm{Zn}$, and graphite furnace atomic absorption spectroscopy was used to analyze $\mathrm{Cu}$ content. BMD was examined using dual energy X-ray absorptiometry. Results Tooth wear patients had reduced lumbar spine, but not femoral, BMD relative to controls $(p<0.001)$. No differences were found in enamel $\mathrm{Ca}$ concentration and $\mathrm{Zn}$ content was slightly higher in tooth wear patients than in controls whereas $\mathrm{Cu}$ content was significantly decreased in the patients: $19.59 \pm 16.4$ vs $36.86 \pm 26.1 \mu \mathrm{g} / 1(p=0.01)$ despite similar levels of $\mathrm{Cu}$ in serum and saliva. The differences were independent of serum 25-OH-D, osteocalcin concentrations or PTH either. Conclusion Severe tooth wear is associated with reduced spinal BMD. Enamel in adult individuals with severe tooth wear is low in copper content. Therefore, further work is needed to determine whether copper plays a role in bone pathophysiology in these patients.

Keywords Bone mineral density $\cdot$ Copper deficit - Dental status · Enamel attrition · Enamel composition ·

Microelements

\section{Introduction}

Teeth and bones are regarded the most mineralized tissues in humans. Several reports suggest association between tooth loss or small number of remaining teeth and reduced bone mineral density (BMD) [1-5]. There is also evidence of the effect of periodontal disease and osteoporosis in the elderly [6-11]. Furthermore, periodontal disease has also been reported an important and common coincidence of systemic bone loss in both women and men [12-16]. It has been 
shown that the reduction of systemic BMD may be a risk factor for the development of tooth loss and oral health problems $[2,7,17]$ suggesting possible cause-effect link, particularly in postmenopausal women with osteoporosis [13, $18,19]$. Some studies also show that dental status impairment related to osteoporosis may result from a considerable decrease of mandibular bone mass [20,21], though the contributing factors remain unclear. Possible mechanisms may include tooth loss during ageing as a natural process secondary to the systemic bone loss; however, the age-related progressive dental decline may also co-exist with deficits in BMD $[17,21]$. These associations are well recognized among the elderly but there are still limited data on such associations in younger age. Accelerated tooth wear appears one of the conditions affecting enamel, independently of age, so that it may occur in younger otherwise healthy people.

It is well known that tooth enamel is the hardest tissue in the human body. Although enamel does not have the typical structure of human bone, its chemical composition is similar. Hydroxyapatite and magnesium phosphate are building minerals essential for bone structure, quality, and resistance whereas some trace elements (i.e., zinc and copper) are very important for bone integrity and elasticity. Enamel is continuously affected by the process of wear. Although the tooth wear is recognized the physiological and irreversible phenomenon, there are individuals in whom this process of wear occurs dramatically faster and, if not treated, may lead to the complete destruction of stomatognathic system [22]. The cause of this acceleration of tooth wear is multifactorial as it is generally a combination of abrasion, attrition, and erosion. [23]. Thus, the processes of local demineralization and remineralization reflecting the erosion-attrition or erosionabrasion play the key role in the clinical picture of wear [24-27].

As underlying mechanisms seem unclear in this condition, it is worth evaluating associations between tooth wear, skeletal status, and potential pathogenic pathways, focused on enamel composition. The effects of microelements such as zinc and copper on tooth demineralization and remineralization have been previously described [28, 29]. Zinc has been reported to reduce enamel solubility $[29,30]$. It has been also suggested that zinc is incorporated into enamel during remineralization in situ despite a moderate level of an increase in zinc concentration [31]. Brookes et al. have further demonstrated that copper has a direct protective effect on the dissolution of enamel in acidic environment, being a major driving force for both caries and erosion [32]. By contrast, Koulourides observed an inhibition of enamel remineralization by $\mathrm{Cu}$, presumably due to ionic interaction with the active enamel surface following demineralization [33].

Beyond an evident significance of calcium-phosphate in bone turnover, the role of micronutrients and elements, i.e., iron, magnesium, manganese, selenium, zinc, and copper is also well known in bone metabolism [34-38]. Trace elements, in particular zinc and copper, are actively participating in enzymatic systems responsible for bone matrix turnover [39]. Zinc is a constituent of approximately 300 enzymes, including those essential for bone metabolism (bone alkaline phosphate) [40]. Copper is another trace element involved in bone metabolism as a cofactor of lysyl oxidase, one of the principal enzymes participating in collagen crosslinking. Animal studies suggest that $\mathrm{Cu}$ deficiency is associated with reduced bone strength and deterioration of bone quality leading to osteoporotic lesions [41].

Considering that enamel represents similar features, qualities, and mineralized components to bone tissues, we aimed to investigate possible associations between enamel mineral composition and BMD in adult patients with tooth wear. We hypothesized that both systemic bone loss (lower BMD) and excessive abrasion of dental enamel coincided in subjects with severe tooth wear.

\section{Patients and methods}

\section{Participants}

In this cross-sectional observational study, 50 participants (16 women, 34 men) aged $47.5 \pm 5$ years with advanced tooth wear were included. The patients were referred to the Department of Prosthetic Dentistry due to clinically apparent decrease of occlusal vertical dimension and a consequent reduced self-esteem of face aesthetics. On average, these subjects possessed 23 teeth. The control group consisted of 20 healthy volunteers aged $46.5 \pm 6$ years (eight women and 12 men), matched by body mass index (BMI), without signs of pathological tooth wear. They were asked to participate voluntary in the study as they presented at the department to make minor prosthetic procedures relating only to a single tooth (e.g., crown or inlay). On average, the reference subjects possessed 27 teeth. All study participants demonstrated good general somatic condition, their own teeth were free of clinical signs of dental caries or periodontal disease. Tooth Wear Index (TWI) was used to categorize the participants.

The inclusion criteria for the studied patients were: the presence of widespread advanced tooth wear with multiple sites of exposed occlusal dentin (TWI on occlusal/incisal surface $\geq 2$ ) and a considerable decrease in the occlusal vertical dimension (more than $4 \mathrm{~mm}$ measured in the anterior region), no significant periodontal bone loss or decay on their own teeth, no prior prosthetic rehabilitation attempting to treat the lost vertical dimension. Furthermore, the inclusion criteria for the whole group encompassed: absence of chronic metabolic, endocrine, renal, or gastrointestinal conditions, or prolonged medication known to affect bone metabolism, oral microflora, or the salivary flow rate. No history of clinically significant 
fractures was reported in either of the groups. Patients who underwent prosthetic rehabilitation prior to recruitment were excluded. The participants were required to be available to be recalled multiple times during the duration of the study. Informed consent was obtained from each participant prior to confirmation of their eligibility for the study. The protocol was approved by the Ethical Committee of the Medical University of Bialystok, Poland (approval \# R-I-003/6/2006).

\section{Methods}

The dietary intakes of nutrients, including elements and vitamin D, were assessed with the validated 7-days foodfrequency questionnaire based on the software DIETA 3, and the obtained data were compared to the national recommended daily intakes (RDIs). Both direct standardized interviewbased questionnaire and medical records were utilized to accomplish medical history. Anthropometric measurements (body weight and height) were performed using electronic scale (Seca, Germany) and Harpenden stadiometer, whereas BMI was calculated using standard formula.

\section{Dental examination and clinical procedures}

All of the participants were clinically examined to evaluate tooth wear. Tooth wear was assessed according to the protocol of Smith and Knight [42]. The TWI was selected as an assessment measure because this method allowed to visually evaluate the level of wear. The maxillary central incisors of each subject underwent acid biopsies to assess the mineral composition of the enamel. The acid biopsy technique was used to determine calcium $(\mathrm{Ca})$, zinc $(\mathrm{Zn})$, and copper $(\mathrm{Cu})$ contents in the tooth enamel [43].

The biopsies were taken between 10-11 AM, i.e., approximately $3 \mathrm{~h}$ after tooth paste use. All study participants were maintaining their customary habits regarding oral hygiene.

The enamel of the labial surface of the maxillary central incisors was cleaned with pumice, rinsed, and dried. Three analytical grade filter paper disks were placed in the middle part of the prepared surface. The diameter of the disks cut out of filter paper was $3 \mathrm{~mm}$, and the paper was empty of any elements. Next, $1 \mu \mathrm{l}$ of $0.1 \mathrm{~mol} / 1$ perchloric acid solution $\left(\mathrm{HClO}_{4}\right)$ was pipetted directly onto the middle of each of these disks. The acid was transferred using a micropipette (Eppendorf Varipipette 4710, Eppendorf-Nethler-Hinz, Germany). The acid was allowed to work on the enamel for $60 \mathrm{~s}$. Immediately after removing the filter paper disks, the biopsy area was rinsed with distilled water and dried. Fluormex gel containing $1.25 \%$ amino-fluorides (Chema, Poland) was applied to the enamel to promote re-mineralization. The biopsies were transferred to $1.5 \mathrm{ml}$ sterilized, capped tubes (Safe-Lock, Eppendorf, Germany), then $1.5 \mathrm{ml}$ of concentrated nitric acid and $0.5 \mathrm{ml}$ of distilled water were added to the samples which were mineralized using microwave mineralization (Uni Clever II, Plazmatronika, Poland). This method was used to completely degrade organic matter and convert it into inorganic substances. One well-qualified person performed all of the biopsies.

The amounts of $\mathrm{Ca}$ and $\mathrm{Zn}$ in the enamel bioptates were established using atomic absorption (AA) spectroscopy with an air/acetylene flame (Hitachi Model Z-500, Spectro, Germany). The concentration of each element was calculated using a calibration curve, and the curve for each element was constructed using the instrument. The concentration of $\mathrm{Cu}$ was measured using an electrothermic method with argon gas on the AA spectrometer, as calculated from the appropriate calibration curve. Reproducibility of the procedure was based on $\mathrm{Ca}, \mathrm{Mg}, \mathrm{Zn}$, and $\mathrm{Cu}$ concentration values reported as the mean value from three tests. Twenty measurements were retested by one investigator who was familiar with the employed methods. The reproducibility agreement was found to be $90 \%$.

Saliva collection was made between 10.00 a.m. and 11 into sterile pot after chewing a stick of spearmint-flavored gum through $5 \mathrm{~min}$. Flow rate, $\mathrm{pH}$, bicarbonate, and element content analyses were performed within $15 \mathrm{~min}$ of saliva collection. The samples were mineralized with concentrated nitric acid in microwave mineralizer (Plazmatronika) and subsequently analyzed for $\mathrm{Ca}, \mathrm{Zn}$, and $\mathrm{Cu}$ concentrations using AAS method.

\section{Bone mineral density measurements}

Dual-energy X-ray absorptiometry (DXA) with the DPX Prodigy equipment (GE-Healthcare Lunar, Madison, WI, USA) was used to determine bone mineral density (BMD, $\mathrm{g} / \mathrm{cm}^{2}$ ) in the antero-posterior lumbar spine region (vertebral bodies L1-L4) and total femur. All scans and analyses were performed by an experienced certified clinical densitometrist (JK). The estimated reproducibility error in vivo (coefficient of variation) was $1.45 \%$, based on duplicate lumbar spine DXA examination performed in 24 subjects. Results were expressed as T-scores and were also compared to age- and sex-matched reference ranges and expressed as Z-scores for BMD according to the NHANES database provided by the manufacturer. The interpretation of the DXA results was based on current practice guidelines of ICSD.

\section{Biochemical analyses}

To determine biochemical parameters, $10 \mathrm{ml}$ of blood taken for coagulum was used. The serum was frozen in the temperature $-80{ }^{\circ} \mathrm{C}$. The concentration of total calcium $(\mathrm{mmol} / \mathrm{L})$, inorganic phosphorus $(\mathrm{mg} / \mathrm{dL})$, total alkaline phosphatase (ALP; IU/L), osteocalcin (ng/mL), parathormone activity (iPTH; pg/mL), and hydroxyvitamin-D [25(OH)D; $(\mathrm{ng} / \mathrm{mL})]$ 
were assessed. Ionized calcium $\left(\mathrm{Ca}^{+2}\right)$ level was evaluated in a 5 -ml blood sample (Siemens lithium heparine syringe).

\section{Statistical analysis}

Statistical analysis of all of the studied attributes was carried out. In the case of quantitative traits, average and dispersion measures were used, i.e., arithmetic mean and standard deviation. The levels of studied attributes between the groups were compared using the $t$ test. The strength of relationships between pairs of measurable parameters was determined using Pearson's correlation coefficient, and its significance was assessed using the $t$ test for the correlation coefficient. The influence of potential factors on a measurable dependent variable, e.g., tooth wear indices, was assessed using analysis of variance. Differences and relationships were considered statistically significant at $p<0.05$.

\section{Results}

Sixteen pre-menopausal women and 34 men aged $47.5 \pm$ 5 years with advanced tooth wear were included in the study and compared with 20 age- and sex-matched healthy peers (12 men, eight premenopausal women) with normal dental status. Based on the clinical examination of 1,017 teeth from patients and 523 teeth from controls, a significant difference in the TWI was found between the groups (Table 1). No associations were observed between TWI and gender, body weight, height, or BMI. There were no differences in anthropometric features between the groups, even if men and women were analyzed separately. Both male and female patients with severe tooth wear demonstrated lower BMD, particularly in the lumbar spine region, compared with their healthy references. This difference remained unaffected and significant after adjustment for sex. The difference in bone density was explicitly expressed in absolute values, T- and Zscores, whereas the results remained within the normal range (Table 1). The patients did not differ from controls in calcium, phosphorus, zinc, copper nor in vitamin D consumption, although in general copper intakes were considerably lower in relation to RDI (Table 2). Furthermore, the dietary intakes of the above nutrients were not associated with the content of the respective elements in the enamel biopsies obtained from either of the groups.

The analysis of biopsies showed difference in copper amount in the enamel between the groups. No correlation between enamel copper and the degree of tooth wear was observed, however, significant difference was found in $\mathrm{Cu}$ content in the enamel between first and second levels of wear $(p=0.04)$. Tooth wear patients had significantly decreased copper content in comparison to controls despite normal salivary and serum concentrations of this element in the two groups (Table 3). Salivary concentrations of calcium, zinc,
Table 1 Characteristics of studied groups including anthropometric traits, dental status, and bone mineral density (BMD)

Mean \pm SD are shown

NS not statistically significant

\begin{tabular}{llll}
\hline & $\begin{array}{l}\text { Tooth wear } \\
\text { patients }(n=50)\end{array}$ & Controls $(n=20)$ & $P$ values \\
\hline Age (years) & $47.5 \pm 5$ & $46.5 \pm 6$ & NS \\
Female/male ratio & $16 / 34$ & $8 / 12$ & \\
Number of teeth (mean; range) & $23(14-28)$ & $27(26-28)$ & NS \\
Tooth Wear Index (TWI) & $2.3 \pm 0.5$ & $0.8 \pm 0.4$ & $<0.001$ \\
Height $(\mathrm{cm})$ & $173.5 \pm 7.2$ & $175.0 \pm 11.1$ & $\mathrm{NS}$ \\
Wright $(\mathrm{kg})$ & $79.2 \pm 9.8$ & $80.4 \pm 11.8$ & $\mathrm{NS}$ \\
Body mass index (BMI) & $26.8 \pm 3.9$ & $26.2 \pm 2.7$ & $\mathrm{NS}$ \\
Women & & & $\mathrm{NS}$ \\
BMD femur [g/cm ${ }^{2}$ ] & $0.93 \pm 0.12$ & $0.97 \pm 0.13$ & $\mathrm{NS}$ \\
T-score for BMD femur & $-0.45 \pm 0.96$ & $-0.17 \pm 1.21$ & $\mathrm{NS}$ \\
Z-score for BMD femur & $0.04 \pm 1.13$ & $0.22 \pm 1.01$ & 0.02 \\
BMD spine [g/cm ${ }^{2}$ ] & $1.08 \pm 0.16$ & $1.23 \pm 0.22$ & 0.02 \\
T-score for BMD spine & $-0.93 \pm 1.33$ & $0.24 \pm 1.97$ & $<0.001$ \\
Z-score for BMD spine & $-0.60 \pm 1.59$ & $0.42 \pm 1.73$ & \\
Men & & & NS \\
BMD femur [g/cm ${ }^{2}$ ] & $1.00 \pm 0.12$ & $1.02 \pm 0.16$ & NS \\
T-score for BMD femur & $-0.52 \pm 0.89$ & $-0.35 \pm 1.24$ & NS \\
Z-score for BMD femur & $-0.15 \pm 0.82$ & $-0.04 \pm 1.18$ & 0.02 \\
BMD spine [g/cm ${ }^{2}$ ] & $1.12 \pm 0.11$ & $1.21 \pm 0.14$ & 0.02 \\
T-score for BMD spine & $-0.92 \pm 0.96$ & $-0.08 \pm 1.08$ & $<001$ \\
Z-score for BMD spine & $-1.08 \pm 0.96$ & & \\
\hline
\end{tabular}


Table 2 Dietary intakes of calcium, zinc, copper, phosphates, and vitamin D in studied subjects

\begin{tabular}{|c|c|c|c|c|c|}
\hline & \multicolumn{2}{|c|}{ Tooth wear patients $(n=50)$} & \multicolumn{2}{|c|}{ Controls $(n=20)$} & \multirow[t]{2}{*}{$P$ values } \\
\hline & Daily amount & $\%$ of RDI & Daily amount & $\%$ of RDI & \\
\hline Calcium (mg) & $762.9 \pm 279.9$ & 94 & $730.8 \pm 269.2$ & 91 & NS \\
\hline Zinc (mg) & $14.03 \pm 4.9$ & 111 & $11.4 \pm 2.8$ & 91 & 0.05 \\
\hline Copper (mg) & $1.57 \pm 0.4$ & 69 & $1.4 \pm 0.3$ & 60 & NS \\
\hline Phosphorus (mg) & $1,585 \pm 521$ & 250 & $1,368 \pm 240$ & 210 & NS \\
\hline Vitamin D $(\mu \mathrm{g})$ & $4.78 \pm 4.5$ & & $3.21 \pm 1.8$ & & NS \\
\hline
\end{tabular}

Mean values \pm SD and \% of recommended daily intakes (RDIs) are shown

NS denote not statistically significant differences

and copper were similar in patients and controls. There were no differences in serum 25-hydroxyvitamin D, PTH activity, or bone formation marker (osteocalcin) between the two groups.

\section{Discussion}

Our study showed coincidence of reduced spine BMD and local enamel copper deficits in a group of patients suffering from a rare disorder: advanced tooth wear. This association was independent of dietary intake of copper or serum content of this element either. Some properties of saliva are considered an important biological factor affecting the rate of dental erosion, transporting ions, and mineralization balance [44, 45]; however, the low enamel copper in our patients was unaffected by salivary concentrations of this trace element. Considering other variables studied, i.e., bone formation markers, PTH, vitamin D status, or menopausal status in women, the decreased copper concentration may potentially play a role in the pathophysiology of mineralized tissues in human body. Whether there is a casual link between the $\mathrm{Cu}$ depletion in situ, susceptibility to lower BMD and advanced tooth abrasion, remains not fully understood.

Several studies in adult populations have documented associations between systemic bone loss in the development of tooth loss [4, 5, 7, 17, 46]. Resorption of tooth-supporting alveolar bone has been regarded as one of the responsible mechanisms [2, 17, 20]. Nonetheless, available data are inconsistent, and usually based on a self-reported tooth count. Most studies have focused on postmenopausal women, but a few reports have shown lower BMD being associated with the number of missing teeth also in men [12, 47]. Whereas certain studies in edentulous elder population have shown reduced BMD at the spine accompanied by higher BMD at the femoral neck [48], others have reported contrasting findings, i.e., lower femoral rather than spine BMD being associated with tooth loss [19]. These teeth-bones relationships relate usually to older people and prove clinical relevance of dental status in postmenopausal osteoporosis.
We extend this observation by demonstrating that the onset of dental disease with precocious rapid enamel abrasion in younger age may also coexist with decreased BMD. The DXA measurement, used in our study, does not allow insight into the structure or quality of bone, so that it is neither able to distinguish between cortical and trabecular bone loss nor between mineral and matrix deterioration. However, in this study, the reduction in BMD was detectable mainly in vertebral bodies, not in the femoral region, suggesting a negative effect on trabecular bone and enamel in individuals with tooth wear. The process affecting both enamel and bone tissue may result from either an earlier demineralization or inadequate bone growth, i.e., deterioration of microstructure. Genetic predisposition for tooth wear has not been yet described in the literature.

Possible underlying mechanisms of the two conditions may include disturbances in some trace elements leading, at least partly, to defective mineral and/or matrix composition in teeth and bones. Evidence supporting this view is available in animal studies reporting negative effect of low dietary intake of copper or its deficiency on bone matrix during growth, producing reduced bone strength and, thereby, the clinically apparent osteoporosis [49, 50]. Chronic exposure of growing rats to marginally low copper has been demonstrated to produce impaired mechanical strength, which predisposed the rats to bone fragility, independently of calcium/phosphate status. The explanation of this pathway focused on deteriorations in the collagen component of bone tissue attributable to defected intermolecular crosslinking which is essentially dependent on lysyl oxidase [51]. Others reported that deficiency of trace elements, including copper as the cofactor of this enzyme, may also play significant role in the pathogenesis of alcohol-induced reduction in bone mineral content in rats [52]. Absence of copper-dependent lysil oxidase in humans has been clearly described as molecular cause of defective bone collagen in Menkes disease [36, 53]. Furthermore, results of animal studies have shown copper deficits in teeth and mandible being linked to experimental postmenopausal osteoporosis 
Table 3 Comparison of calcium, zinc, and copper contents in enamel bioptates, saliva; serum concentrations of the elements, and serum levels of hydroxyvitamin $\mathrm{D}, \mathrm{PTH}$, and bone formation marker (mean values $\pm \mathrm{SD}$ are given)

$N S$ denote not statistically significant differences

\begin{tabular}{llll}
\hline & Tooth wear patients $(n=50)$ & Controls $(n=20)$ & $P$ values \\
\hline Enamel & & & \\
$\mathrm{Ca}[\mathrm{mg} / \mathrm{L}]$ & $1.884 \pm 1.382$ & $1.853 \pm 1.241$ & $\mathrm{NS}$ \\
$\mathrm{Zn}[\mathrm{mg} / \mathrm{L}]$ & $0.142 \pm 0.041$ & $0.084 \pm 0.022$ & 0.05 \\
$\mathrm{Cu}[\mu \mathrm{g} / \mathrm{L}]$ & $19.861 \pm 13.171$ & $36.673 \pm 22.661$ & 0.01 \\
$\mathrm{Saliva}$ & & & \\
$\mathrm{Ca}[\mathrm{mg} / \mathrm{L}]$ & $61.691 \pm 36.851$ & $70.771 \pm 57.572$ & $\mathrm{NS}$ \\
$\mathrm{Zn}[\mathrm{mg} / \mathrm{L}]$ & $2.043 \pm 1.511$ & $2.652 \pm 1.792$ & $\mathrm{NS}$ \\
$\mathrm{Cu}[\mu \mathrm{g} / \mathrm{L}]$ & $114.644 \pm 78.362$ & $78.321 \pm 61.691$ & $\mathrm{NS}$ \\
$\mathrm{Serum}$ & & & \\
$\mathrm{Ca}{ }^{++}$ionized $(\mathrm{mmol} / \mathrm{L})$ & $1.21 \pm 0.07$ & $1.20 \pm 0.06$ & $\mathrm{NS}$ \\
$\mathrm{Ca}(\mathrm{mmol} / \mathrm{l})$ & $2.36 \pm 0.10$ & $2.36 \pm 0.11$ & $\mathrm{NS}$ \\
$\mathrm{Zn}[\mathrm{mg} / \mathrm{L}]$ & $1.042 \pm 0.242$ & $1.161 \pm 0.222$ & $\mathrm{NS}$ \\
$\mathrm{Cu}[\mathrm{mg} / \mathrm{L}]$ & $0.741 \pm 0.205$ & $0.713 \pm 0.212$ & $\mathrm{NS}$ \\
$\mathrm{Phosphate}(\mathrm{mg} / \mathrm{dL})$ & $3.16 \pm 0.51$ & $3.08 \pm 0.55$ & $\mathrm{NS}$ \\
$\mathrm{PTH}(\mathrm{pg} / \mathrm{mL})$ & $58.69 \pm 28.31$ & $56.56 \pm 22.04$ & $\mathrm{NS}$ \\
25(OH)D (ng/mL) & $24.33 \pm 6.29$ & $22.19 \pm 5.63$ & $\mathrm{NS}$ \\
Alkaline phosphatase (sALP) $[\mathrm{IU} / \mathrm{L}]$ & $55.14 \pm 15.81$ & $62.35 \pm 17.59$ & $\mathrm{NS}$ \\
Osteocalcin $(\mathrm{ng} / \mathrm{mL})$ & $19.87 \pm 6.05$ & $18.75 \pm 4.62$ & $\mathrm{NS}$ \\
\hline
\end{tabular}

in the whole skeleton [54]. These findings, although not directly relating to humans, suggest an important role of copper deficit in the impairment of mineralized tissues and, therefore, could support our hypothesis. Lichtenegger et al. reported an interesting constellation of biominerals in living organisms demonstrating high abrasion resistance, stiffness, and hardness of the jaws of Glycera dibranchiata due to the content and specific distribution of copper [55]. The investigators proved that copper-based biomineral atacamite formed in polycrystalline fibers was the key component enhancing an extraordinary resistance to abrasion despite generally sparse mineralization.

There are limited published data on the significance of trace elements in postmenopausal osteoporosis whereas none of the reports focused on bone status in younger population. Most of previous clinical studies provide evidence of beneficial role of copper and zinc in improvement of bone density and quality in both osteoporotic and healthy individuals, particularly found in cancellous bone, i.e., lumbar spine vertebrae [56-58]. Additional intake of trace elements was reported to positively and independently influence maintenance of spinal BMD in calcium-supplemented non-osteoporotic women [56]. Available data remain inconsistent, e.g., Mutlu et al. found considerably lower serum $\mathrm{Zn}$ and $\mathrm{Mg}$ levels, but not $\mathrm{Cu}$ concentration, in osteoporotic women, however, their study was based only on DXA examination of the femoral neck [59]. In our tooth wear patients, we report a site-specific relationship between decreased copper content in enamel and reduced BMD in the lumbar spine region. Interestingly, both patients and controls (even considering a limited number of the controls) had suboptimal and similar copper intakes from diets, and did not differ in serum or salivary $\mathrm{Cu}$ concentrations, but only those with severe tooth wear demonstrated lower spinal BMD. This finding may reflect strictly local mechanisms of $\mathrm{Cu}$ deficits responsible for deleterious metabolism in hard tissues. Furthermore, this association may have appeared due to intensive bone turnover more pronounced in trabecular bones of vertebrae than in long bones. Both animal studies [49] and an interesting historical study using human bone samples obtained from autopsies [60] supported our observation.

We acknowledge that the excessive enamel erosion accompanied by unusual abrasive processes, both being core issues in tooth wear, could not be directly compared with porosity or trabecular thinning in bone, which appear essential in osteoporosis. Nevertheless, there is a lot of analogy regarding the final outcome indicating similar impairment of the quality and strength on the tissue level. A limitation of our study results from methodological aspects, i.e., the use of quantitative DXA method which is regarded only a surrogate of bone strength or quality. Thus, it is possible that bone biopsies, histomorphometry or high-resolution QCT of the skeleton, might detect true associations between trace element content and structure of bone, but those methods were unavailable. Moreover, the complexity of the interrelationships between micronutrients and their metabolic effects justifies certain controversies regarding the causal pathways and contribution of a single trace element to BMD, bone quality, or enamel structure and resistance. These limitations, however, do not detract from our main findings. 
In conclusion, our data suggest that severe tooth wear is associated with an increased risk of reduced BMD in adults, with an effect expressed particularly in the lumbar spine. As enamel is low in copper content in the individuals with tooth wear, there is a possibility that defective metabolism of this trace element may contribute to coincidence of the two conditions. Nonetheless, larger prospective studies are needed to determine whether copper plays a role in bone pathophysiology in tooth wear patients and to elucidate whether systematic supplementation of copper would alleviate decline in BMD and precocious enamel abrasion.

\section{Conflicts of interest None.}

Open Access This article is distributed under the terms of the Creative Commons Attribution Noncommercial License which permits any noncommercial use, distribution, and reproduction in any medium, provided the original author(s) and the source are credited.

\section{References}

1. Dervis E (2005) Oral implications of osteoporosis. Oral Surg Oral Med Oral Pathol Oral Radiol Endod 100:349-356

2. Taguchi A, Suei Y, Ohtsuka M, Otani K, Tanimoto K, Hollender LG (1999) Relationship between bone mineral density and tooth loss in elderly Japanese women. Dentomaxillofac Radiol 28:219223

3. Becker AR, Handick KE, Roberts WE, Garetto LP (1997) Osteoporosis risk factors in female dental patients. A preliminary report. J Indiana Dent Assoc 76:15-19

4. Mattson JS, Cerutis DR, Parrish LC (2002) Osteoporosis: a review and its dental implications. Compend Contin Educ Dent 23:10011004

5. Yoshihara A, Seida Y, Hanada N, Nakashima K, Miyazaki H (2005) The relationship between bone mineral density and the number of remaining teeth in community-dwelling older adults. J Oral Rehabil 32:735-740

6. Tozum TF, Taguchi A (2004) Role of dental panoramic radiographs in assessment of future dental conditions in patients with osteoporosis and periodontitis. N Y State Dent J 70:32-35

7. Mohammad AR, Hooper DA, Vermilyea SG, Mariotti A, Preshaw PM (2003) An investigation of the relationship between systemic bone density and clinical periodontal status in post-menopausal Asian-American women. Int Dent J 53:121-125

8. Taguchi A, Suei Y, Ohtsuka M, Nakamoto T, Lee K, Sanada M, Tsuda M, Ohama K, Tanimoto K, Bollen AM (2005) Relationship between self-reported periodontal status and skeletal bone mineral density in Japanese postmenopausal women. Menopause 12:144-148

9. Bando K, Nitta H, Matsubara M, Ishikawa I (1998) Bone mineral density in periodontally healthy and edentulous postmenopausal women. Ann Periodontol 3:322-326

10. Lundstrom A, Jendle J, Stenstrom B, Toss G, Ravald N (2001) Periodontal conditions in 70-year-old women with osteoporosis. Swed Dent J 25:89-96

11. Yoshihara A, Seida Y, Hanada N, Miyazaki H (2004) A longitudinal study of the relationship between periodontal disease and bone mineral density in community-dwelling older adults. J Clin Periodontol 31:680-684

12. Elders PJ, Habets LL, Netelenbos JC, van der Linden LW, van der Stelt PF (1992) The relation between periodontitis and systemic bone mass in women between 46 and 55 years of age. J Clin Periodontol 19:492-496

13. Inagaki K, Kurosu Y, Kamiya T, Kondo F, Yoshinari N, Noguchi T, Krall EA, Garcia RI (2001) Low metacarpal bone density, tooth loss, and periodontal disease in Japanese women. J Dent Res 80:1818-1822

14. Weyant RJ, Pearlstein ME, Churak AP, Forrest K, Famili P, Cauley JA (1999) The association between osteopenia and periodontal attachment loss in older women. J Periodontol 70:982-991

15. Inagaki K, Kurosu Y, Yoshinari N, Noguchi T, Krall EA, Garcia RI (2005) Efficacy of periodontal disease and tooth loss to screen for low bone mineral density in Japanese women. Calcif Tissue Int 77:9-14

16. Famili P, Cauley J, Suzuki JB, Weyant R (2005) Longitudinal study of periodontal disease and edentulism with rates of bone loss in older women. J Periodontol 76:11-15

17. Krall EA, Garcia RI, Dawson-Hughes B (1996) Increased risk of tooth loss is related to bone loss at the whole body, hip, and spine. Calcif Tissue Int 59:433-437

18. Krall EA, Dawson-Hughes B, Papas A, Garcia RI (1994) Tooth loss and skeletal bone density in healthy postmenopausal women. Osteoporos Int 4:104-109

19. Taguchi A, Fujiwara S, Masunari N, Suzuki G (2004) Self-reported number of remaining teeth is associated with bone mineral density of the femoral neck, but not of the spine, in Japanese men and women. Osteoporos Int 15:842-846

20. Taguchi A, Tanimoto K, Suei Y, Wada T (1995) Tooth loss and mandibular osteopenia. Oral Surg Oral Med Oral Pathol Oral Radiol Endod 79:127-132

21. Nitta H, Ishikawa I (2003) Skeletal and mandibular bone mineral density in dentate and edentulous postmenopausal women. Clin Calcium 13:594-598

22. Dahl BL, Carlsson GE, Ekfeldt A (1993) Occlussal wear of teeth and restorative materials. A review of classification, etiology, mechanisms and some aspects of restorative procedures. Acta Odontol Scand 51:299-311

23. Bartlett DW, Shah P (2006) A critical review of non-carious cervical (wear) lesions and the role of abfraction, erosion and abrasion. J Dent Res 85:306-312

24. Jaeggi T, Lussi A (1999) Tooth brush abrasion of erosively altered enamel after intraoral exposure to saliva: an in situ study. Caries Res 33:455-461

25. Attin T, Buchalla W, Gollner M, Hellwig E (2000) Use of variable remineralisation period to improve the abrasion resistance of previously eroded enamel. Caries Res 34:48-52

26. Eisenburger M, Addy M (2002) Erosion and attrition of human enamel in vitro. Part: I Interaction effects. J Dent 30:341-347

27. Eisenburger M, Addy M (2002) Erosion and attrition of human enamel in vitro. Part II: Influence of time and loading. J Dent 30:349-352

28. Abdullah AZ, Strafford SM, Brookes SJ, Duggal MS (2006) The effect of copper on demineralization of dental enamel. J Dent Res 85:1011-1015

29. Churchley D, Newby CS, Willson R, Haider A, Schemehorn B, Lynch RJM (2011) Protection against enamel demineralization using toothpastes containing o-cumen-5-ol, zinc chloride and sodium fluoride. Int Dent J 61(suppl 3):55-59

30. Lynch RJM (2011) Zinc in the mouth, its interactions with dental enamel and possible effects on caries; a review of the literature. Int Dent J 61(suppl 3):46-54

31. Matsunaga T, Ishizaki H, Tanabe S (2009) Synchrotron radiation microbeam X-ray fluorescence analysis of zinc concentration of remineralised enamel in situ. Arch Oral Biol 54:420-423

32. Brookes SJ, Shore RC, Robinson C, Wood SR, Kirham J (2003) Copper ions inhibit the demineralization of human enamel. Arch Oral Biol 48:25-30

33. Koulourides T, Feagin F, Pigman W (1968) Effect of pH, ionic strength, and cupric ions on the rehardening rate of buffer-softened human enamel. Arch Oral Biol 13:335-341 
34. Abraham R, Walton J, Russell L, Wolman R, Wardley-Smith B, Green JR, Mitchell A, Reeve J (2006) Dietary determinants of postmenopausal bone loss at the lumbar spine: a possible beneficial effect of iron. Osteoporos Int 17(8):1165-1173

35. Tucker KL (2003) Dietary intake and bone status with aging. Curr Pharm Des 9(32):2687-2704

36. Olivares M, Uauy R (1996) Copper as an essential nutrient. Am J Clin Nutr 63(5):791S-796S

37. Odabasi E, Turan M, Aydin A, Akay C, Kutlu M (2008) Magnesium, zinc, copper, manganese, and selenium levels in postmenopausal women with osteoporosis. Can magnesium play a key role in osteoporosis? Ann Acad Med Singapore 37(7):564-567

38. Palacios C (2006) The role of nutrients in bone health, from A to Z. Crit Rev Food Sci Nutr 46(8):621-628

39. Branca F, Valtueña S (2001) Calcium, physical activity and bone health-building bones for a stronger future. Public Health Nutr 4(1A):117-123

40. Vallee BL, Falchuk KH (1993) The biochemical basis of zinc physiology. Physiol Rev 73:79-118

41. Medeiros DM, Ilich J, Ireton J, Matkovic V, Shiry L, Wildman R (1997) Femurs from rats fed diets deficient in copper or iron have decreased mechanical strength and altered mineral composition. J Trace Elem Exp Med 10:197-203

42. Smith B, Knight J (1984) An Index for measuring the wear of teeth. Br Dent J 156:435-438

43. Milosevic A, Dawson LJ (1996) Salivary factors in vomiting bulimics with and without pathological tooth wear. Caries Res 30:361-366

44. Featherstone JD, Lussi A (2006) Understanding the chemistry of dental erosion. Monogr Oral Sci 20:66-76

45. Lussi A, Jaeggi T (2006) Chemical factors. Monogr Oral Sci 20:77-87

46. Mohammad AR, Bauer RL, Yeh CK (1997) Spinal bone density and tooth loss in a cohort of postmenopausal women. Int J Prosthodont 10:381-385

47. May H, Reader R, Murphy S, Khaw KT (1995) Self-reported tooth loss and bone mineral density in older men and women. Age Ageing 24:217-221

48. Gur A, Nas K, Kayhan O, Atay MB, Akyuz G, Sindal D et al (2003) The relation between tooth loss and bone mass in postmenopausal osteoporotic women in Turkey: a multicenter study. J Bone Miner Metab 21:43-47

49. Roughead ZK, Lukaski HC (2003) Inadequate copper intake reduces serum insulin-like growth factor-I and bone strength in growing rats fed graded amounts of copper and zinc. J Nutr 133(2):442-448

50. Klevay LM, Wildman RE (2002) Meat diets and fragile bones: inferences about osteoporosis. J Trace Elem Med Biol 16(3):149-154

51. Jonas J, Burns J, Abel EW, Cresswell MJ, Strain JJ, Paterson CR (1993) Impaired mechanical strength of bone in experimental copper deficiency. Ann Nutr Metab 37(5):245-252

52. Preedy VR, Baldwin DR, Keating JW, Salisbury JR (1991) Bone collagen, mineral and trace element composition, histomorphometry and urinary hydroxyproline excretion in chronically-treated alcohol-fed rats. Alcohol Alcohol 26(1):39-46

53. Kanumakala S, Boneh A, Zacharin M (2002) Pamidronate treatment improves bone mineral density in children with Menkes disease. J Inherit Metab Dis 25(5):391-398

54. Rahnama M (2002) Influence of estrogen deficiency on the copper level in rat teeth and mandible. Ann Univ Mariae Curie Sklodowska [Med] 57(1):352-356

55. Lichtenegger HC, Schöberl T, Bartl MH, Waite H, Stucky GD (2002) High abrasion resistance with sparse mineralization: copper biomineral in worm jaws. Science 298(5592):389-392

56. Strause L, Saltman P, Smith KT, Bracker M, Andon MB (1994) Spinal bone loss in postmenopausal women supplemented with calcium and trace minerals. J Nutr 124(7):1060-1064

57. Saltman PD, Strause LG (1993) The role of trace minerals in osteoporosis. J Am Coll Nutr 12:384-389

58. Gür A, Colpan L, Nas K, Cevik R, Saraç J, Erdoğan F, Düz MZ (2002) The role of trace minerals in the pathogenesis of postmenopausal osteoporosis and a new effect of calcitonin. J Bone Miner Metab 20(1):39-43

59. Mutlu M, Argun M, Kilic E, Saraymen R, Yazar S (2007) Magnesium, zinc and copper status in osteoporotic, osteopenic and normal post-menopausal women. J Int Med Res 35(5):692-695

60. Lappalainen R, Knuuttila M, Lammi S, Alhava EM, Olkkonen H (1982) $\mathrm{Zn}$ and $\mathrm{Cu}$ content in human cancellous bone. Acta Orthop Scand 53(1):51-55 